\title{
The status of industrial and municipal effluent treatment with membrane bioreactor technology
}

Judd, S.J., Qatar University/Cranfield University

Simon.judd@qu.edu.qa, 00097444034161

s.j.judd@cranfield.ac.uk, 00441234758310

\section{Abstract}

The status of MBR technology has been scrutinised with reference to (a) available commercial technologies and their characteristics, (b) key design and performance parameters of existing full-scale installations, and (c) practitioner perception. The key design and operating parameters of flux and COD removal were considered with reference to 100 installations, 40 based on municipal and 60 on industrial wastewater treatment. The perception of practitioners was appraised through a conventional survey, with 186 respondents.

A review of the commercial products revealed polyvinylidene difluoride (PVDF) to be the most prevalent membrane material, accounting for almost half of all products, and provided both in flat sheet (FS) and hollow fibre (HF) configurations. Polyethylsulphone (PES) and polyolefinic membranes (polyethylene, PE and polypropylene, PP) were also found to be available in FS and HF configurations respectively. Almost all products had a nominal membrane pore size between 0.03 and $0.4 \mu \mathrm{m}$.

Design fluxes in $\mathrm{L} \mathrm{m}^{-2} \mathrm{~h}^{-1}(\mathrm{LMH})$ for municipal wastewater treatment were predominantly in the 15-25 LMH range, 18.5 $\pm 4.8 \mathrm{LMH}$ on average, for the average daily flow (ADF), and in the 20-30 LMH range, 26.0 $\pm 6.6 \mathrm{LMH}$ on average, for peak daily flow (PDF). Fluxes were lower, and dependent on both process configuration and effluent quality, for industrial effluents; the most challenging effluents (landfill leachate) were associated with the lowest fluxes. As expected, treatment capability related roughly to the feedwater BOD/COD ratio, with more than $90 \%$ COD removal achieved for food and beverage effluents (for which BOD/COD ratios were largely above 0.5) - comparable with municipal wastewater treatment.

Respondents to the survey, around $85 \%$ of whom were practitioners, identified pre-treatment (screening) as presenting the greatest technical challenge to MBR operation.

Keywords Membrane bioreactor; flux; COD removal; municipal wastewater; industrial effluent; practitioners 


\section{Introduction}

Membrane bioreactors (MBRs) combine biological treatment (generally aerobic) with membrane filtration to produce clarified and largely disinfected effluent. The technology is becoming increasingly favoured for wastewater applications where a high treated water quality is required, in particular for its reuse, and where space is limited. All geographical regions appear to be experiencing a comparatively high rate of expansion (expressed as compound annual growth rate, CAGR) of the MBR market, with reference to the GDP of the country in which the technology is being installed. MBRs are now implemented in more than 200 countries and global market growth rates of up to $15 \%$ are regularly reported in various market analyses [1-3], although regional variations are significant. MBR technology total market value is expected to reach almost $\$ 3 \mathrm{~b}$ by 2019 [3] from around $\$ 1.2 \mathrm{~b}$ currently. Confidence in the process appears to be increasing as the number and size of reference installations grows, with around 40 municipal plants over 100 megalitres/day (MLD) in capacity (expressed as peak daily flow, or PDF) now installed and a total global installed capacity probably exceeding 15,000 MLD. Industrial effluent treatment installations of more than 50 MLD capacity now exist.

There have been a large number of predominantly scientific reviews of aerobic MBR technology over the past five years featuring topics such as:

- membrane fouling [4-7],

- specific applications such as industrial effluent treatment [8-9], nutrient removal [10-11] and micropollutant removal [12-13] - primarily at bench or pilot scale,

- modelling of either the biological process [5-6, 14-16] or the fluid dynamics [17-18], and

- process control [19].

It is of interest to both the practitioner and academic communities to appraise the current status of the technology with reference to:

a) the available commercial MBR membrane technologies,

b) the key governing design, operation and maintenance parameter values pertaining to the most commercially-significant applications, and

c) the perception of the practitioner community of the shortcomings and challenges of the technology.

The current review considers the above aspects with reference to the membrane product specifications, accessible data from full-scale installations (100 in all), and a survey of practitioners. This wholly pragmatic approach provides an insight into the actual performance and real-world issues of the technology.

\section{Membrane materials and modules}

Membrane modules for MBRs are either configured as flat sheets (FS) or else have cylindrical geometry (Fig. 1). The latter comprise hollow fibre (HF) and multitube (MT), the key difference in these being the lumen diameter and the direction of flow. HF membranes - the most commercially important in terms of installed area - are narrow filaments (almost all between 0.4 and $2.6 \mathrm{~mm}$ ) where permeate flow is from out to in (or shell-side to lumen-side). MT membranes are wider (generally 5 to $12 \mathrm{~mm}$ as applied to MBRs) with flow in to out (lumenside to shell-side).

The MBR process is configured either with the membranes placed outside or inside a tank (Fig. 2). If immersed (i.e. an iMBR) the permeate is extracted either under suction pressure on the permeate side and/or through the static head of pressure on the retentate side. If external and operated as a sidestream (SMBR) the water permeates the membrane under pressure, the required transmembrane pressure (TMP) being generally much higher than that used for the 
immersed configuration. In general, the more benign conditions of the iMBR configuration make it conducive to municipal wastewaters (i.e. sewage), which are usually less challenging than industrial effluents.

The range of membrane materials employed commercially for MBR technologies is fairly limited, and rated pore sizes are generally in the range between 0.03 and $0.4 \mu \mathrm{m}$. Around half of the polymeric MBR membranes (25 of the 51 products where information is provided) are based on polyvinylidene difluoride, or PVDF (Fig. 1); most of the others are either polyolefinic (polypropylene, PP, or polyethylene, PE) or polyethylsulphone (PES). There are also a growing number of ceramic products, with FS ceramic membranes representing the most recent innovation (four products introduced since 2010).

Whilst there are many membrane module products, a number of membranes have the same specifications which suggests that the number of membrane material suppliers may be limited. For example, the 7-8 immersed PES membranes are offered exclusively as FS and are all 0.03 $\mu \mathrm{m}$ (or $150 \mathrm{kDa}$ ) rated. The two recognisable PE FS membranes are $0.4 \mu \mathrm{m}$ in pore size and hydrophilicised. Also, the nature of the material can limit the viable pore size some materials: the five PE membrane products are almost all offered with pore sizes of $0.2-0.4 \mu \mathrm{m}$, as are the PTFE membranes. Against this, the versatility of the respective manufacturing processes means that PVDF and ceramic membranes are both offered in a wide range of pore sizes.

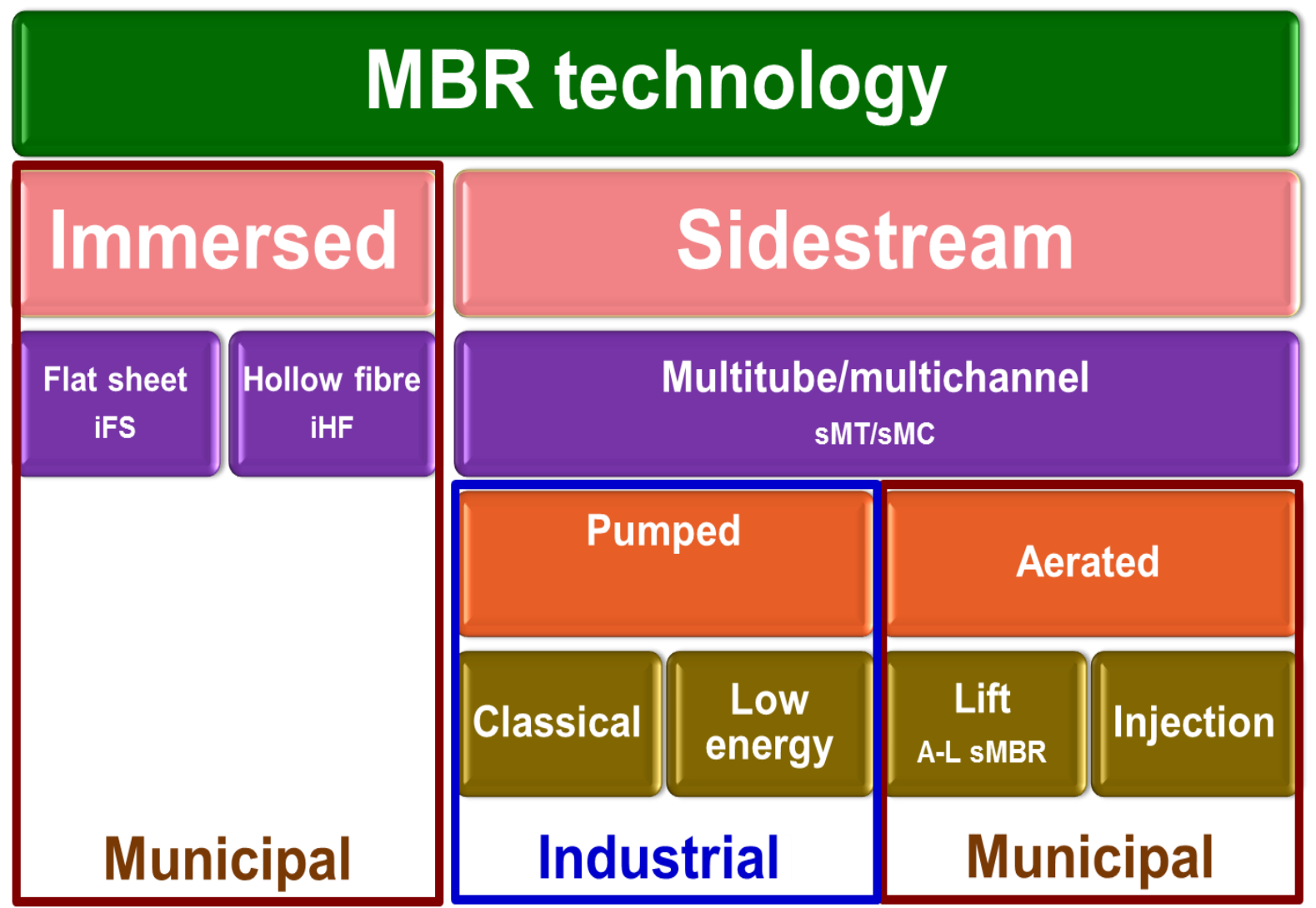

Figure 1. MBR process and membrane configurations, with the predominant application indicated 


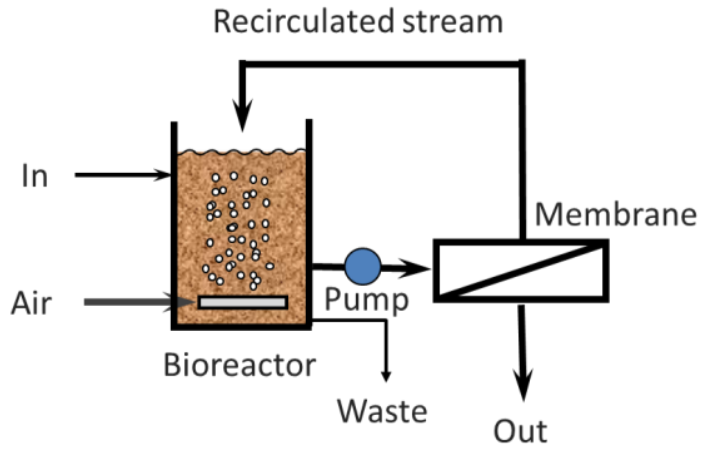

(a)

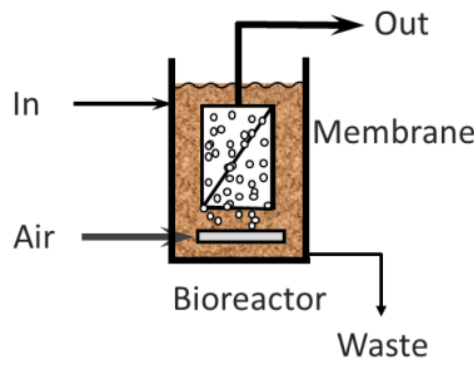

(b)

Figure 2. (a) Sidestream (external) and (b) immersed (internal) MBR configurations [20]

Notwithstanding the wide array of commercial membrane module products available - around 70 if all the Chinese suppliers are included [20-21] - the actual market as represented by installed capacity is dominated by a few global players. The latter have all been established for at least 10 years, and three of them pioneered the immersed technology in the early-mid 1990s. So, whilst there are only two examples of hydrophilicised PE, one of these (the Kubota product) is the most well-established and commercially successful of all the FS products. Against this the use of ceramic membranes is currently limited to a very small number of niche applications, as much by their capital cost than anything else. The four FS ceramic products have all been introduced since 2010, and their projected success cannot be estimated. Other constraints on market penetration are more related to business culture. Installations based on the large range of Chinese membrane products, which are on average $~ 40 \%$ lower in price than Western products [21], are predominantly in China, where the treatment capacity is significant. Similar geographical restrictions apply to the Korean membrane products.

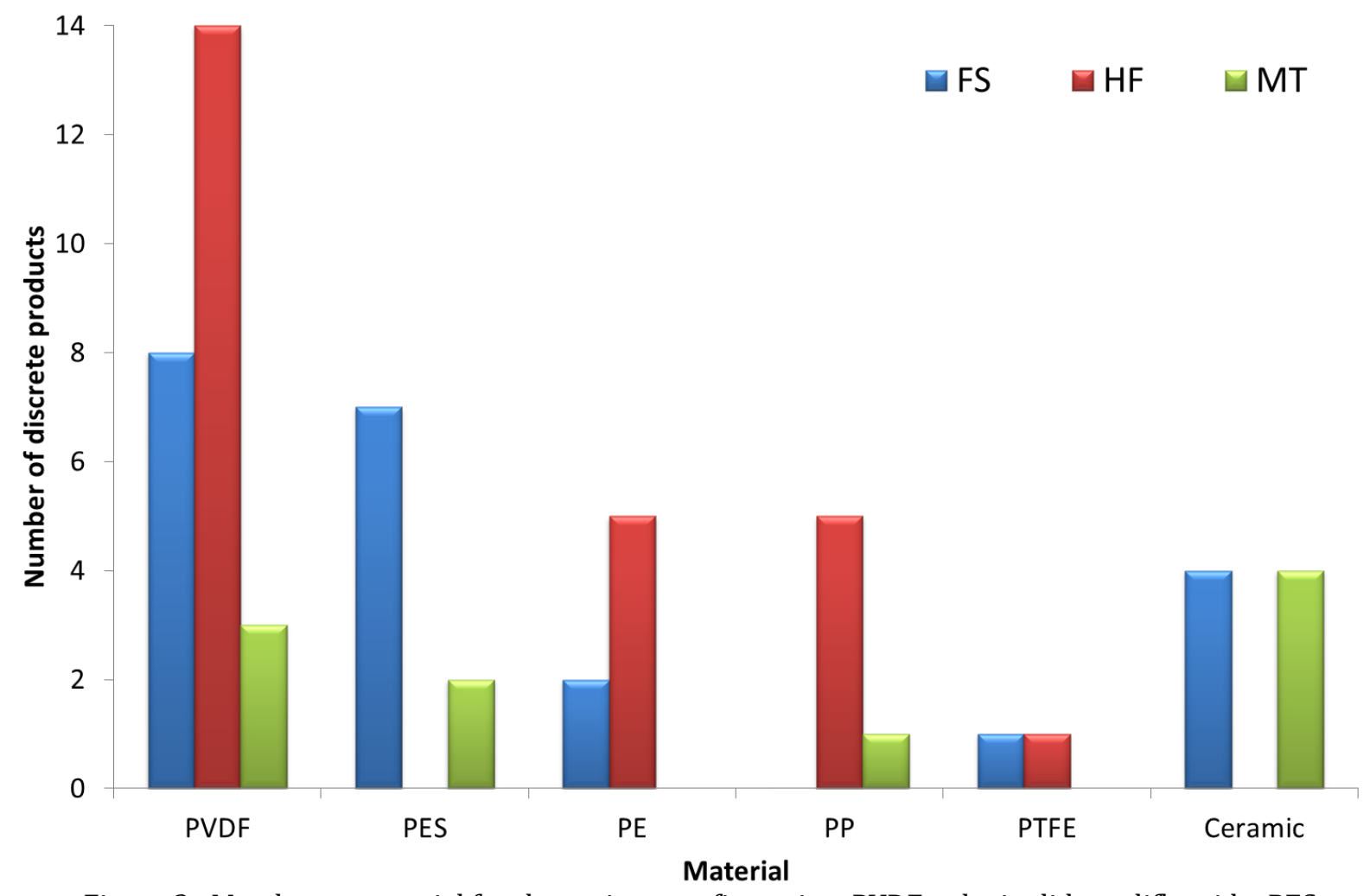

Figure 3. Membrane material for the various configuration. PVDF polyvinylidene difluoride; PES polyethylsulphone; PE polyethylene; PP polypropylene; PTFE polytetrafluoroethylene (data extracted from [20]) 


\section{Design and O\&M}

\subsection{Basis of appraisal}

Regardless of the precise commercial technology, the key design and operation and maintenance $(0 \& M)$ parameters of an MBR installation relate largely to (a) the flow and pressure of water and air, and (b) the degree of water purification attained, as with any wastewater treatment process. In the case of MBRs, the most crucial design parameter is the permeate flux, or the flow rate of water per unit membrane area in $\mathrm{L} \mathrm{m}^{-2} \mathrm{~h}^{-1}(\mathrm{LMH})$. This then determines the fouling rate, or the rate of increase in transmembrane pressure (TMP) with time, which in turn determines how often the membrane is cleaned and the methods adopted for cleaning. The flux, membrane filtration and cleaning cycle periods, and specific energy demand (SED or $E$ in $\mathrm{kWh}$ per $\mathrm{m}^{3}$ permeate) for membrane operation relate more to the MBR process and membrane configuration (Fig. 1) than to specific commercial technology. Energy is consumed by the application of shear, generated either through air scouring of immersed membranes, in which case the key parameter is the specific aeration demand with respect to membrane area $\left(\mathrm{SAD}_{\mathrm{m}}\right.$ in $\left.\mathrm{Nm}^{3} /\left(\mathrm{m}^{2} . \mathrm{h}\right)\right)$, or through the crossflow velocity (CFV) for pumped sidestream membranes. The degree of purification with respect to organic carbon removal is normally represented by removal of COD (chemical oxygen demand) for industrial effluent treatment and BOD (biochemical oxygen demand) for municipal effluent treatment. Other important water quality determinants include the nutrients, quantified variously as ammonia $\left(\mathrm{N}-\mathrm{NH}_{4}\right)$, Total Kjeldahl nitrogen (TKN), total nitrogen (TN) and total phosphorus (TP).

A review of the $0 \& \mathrm{M}$ and performance parameters is provided with reference to a total of 100 installations are considered, 40 based on municipal effluent and 60 on industrial, encompassing all MBR membrane configurations and process configurations (Fig. 1). Performance is appraised primarily with reference to flux and COD or BOD removal, with other key aspects of O\&M, such as the bioreactor solids concentration (or mixed liquor suspended solids, MLSS) also considered. Data is sourced from key texts [20, 22-23], key review articles [8] and individual case studies either published in peer reviewed literature [24-26] presented at conferences or workshops [27-29], or provided as "grey" literature, such as reports [30] or on line posts [31].

\subsection{Flow and flux}

Technology performance tends to change with flow, and hence the difference between the average and peak daily flow (ADF and PDF respectively) is of some importance, the PDF/ADF ratio being the peak loading factor (PLF). For industrial effluents the significant changes in both flow and loads normally justify equalisation (EQ) with an appropriately sized buffer tank as pretreatment, whereas EQ is not normally favoured for municipal effluents. Data from 44 municipal installations suggests the PLF to be predominantly in the range 1.5-2.5 (Fig. 4a) with, perhaps counterintuitively, no correlation with flow (Fig. 4b). This becomes important when considering the design flux and associated installed membrane area, since a judgement must be made as to the flux sustainable over the short periods of peak flow compared to that during normal flow.

A review of the available flux data across all iMBRs (comprising 39 municipal and 40 industrial wastewater treatment installations) reveals that design fluxes selected for industrial effluents are more conservative than those for municipal applications, even for the most benign of industrial effluents, arising from food and beverage (Fig. 5a). Flux values for industrial effluents vary significantly with wastewater type and, as would be expected, technology type. These data are very highly scattered: there is no apparent trend with application for the 13 food and beverage data or the 23 industrial installations data (all data other than landfill leachate) for which data are available. Indeed, both the mean and standard deviation values for these two groups of data are very similar (14.4 vs. 14.1 LMH mean flux; $37 \%$ vs. $34 \%$ standard deviation, 
Table 1). However, an examination of the range of fluxes for the different wastewater types (Fig. $5 b)$ reveals that 34 of the 39 iMBRs reviewed operate at a mean flux between 5 and $30 \mathrm{LMH}$.

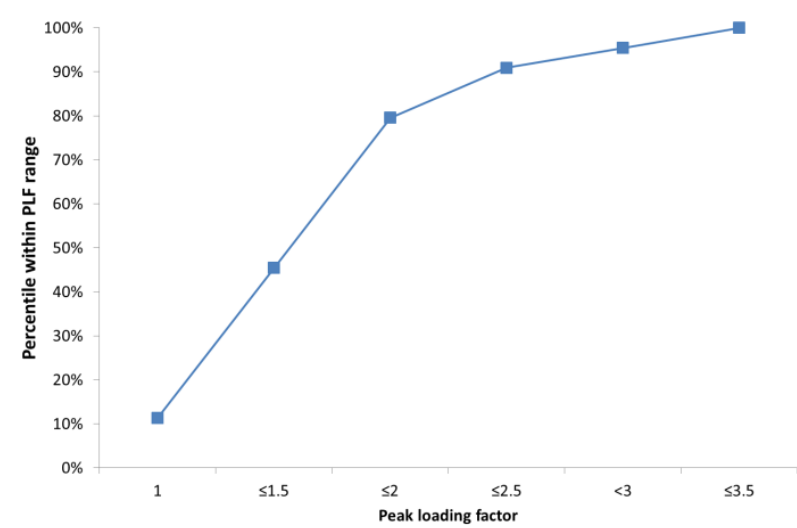

(a)

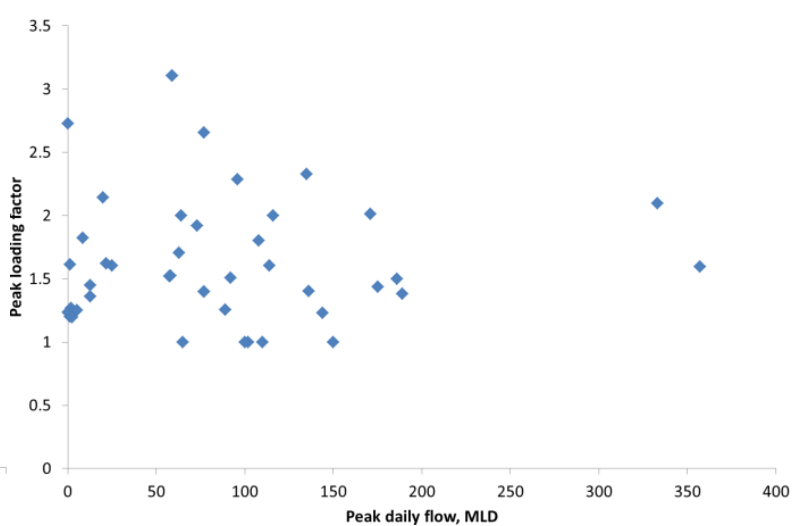

(b)

Figure 4. Peak loading factor data, municipal installations (a) values within ranges, and (b) correlation with installed flow capacity

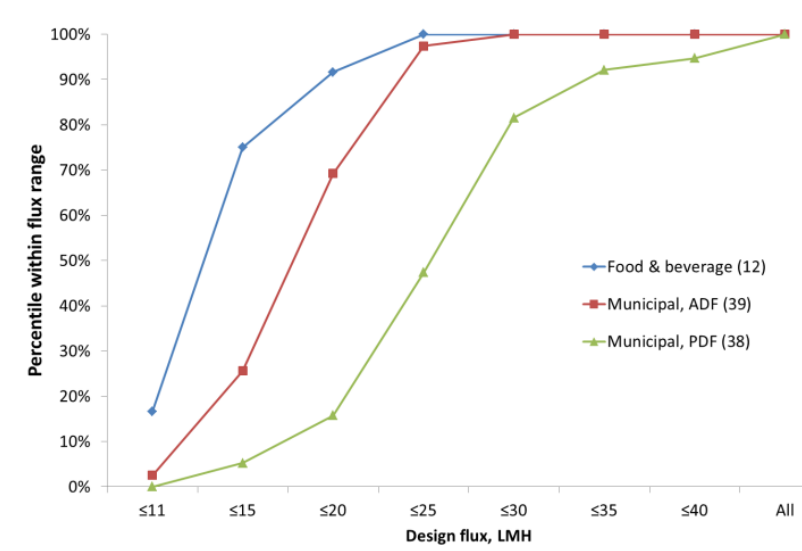

(a)

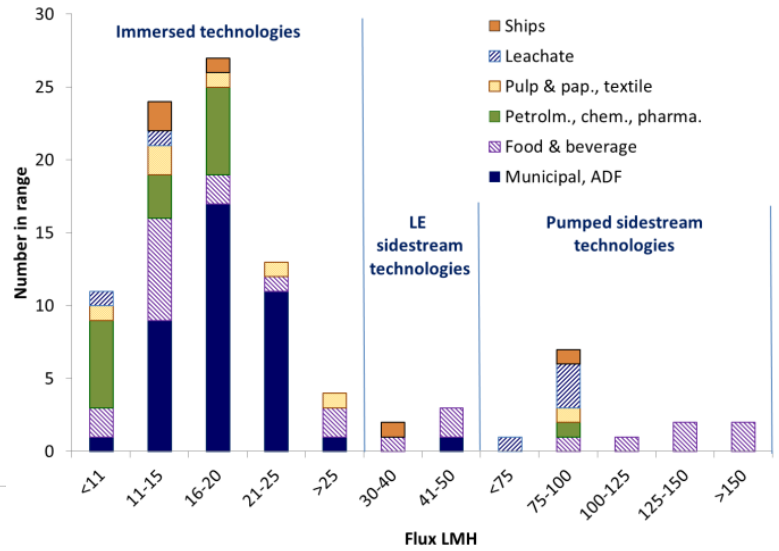

(b)

Figure 5. Design flux data, iMBRs: (a) Food and beverage effluent vs. municipal, (b) all municipal (39 reference sites) and industrial (57 reference sites)wastewaters: immersed, low-energy sidestream (including air-lift) and conventional pumped sidestream (adapted from [20])

Table 1: Summary of flux data, 38 municipal and 48 industrial reference sites

\begin{tabular}{l|llllll}
\hline Sector(s) & Technology & Min & Max & Ave & SD & No. data \\
\hline Municipal & iMBR, PDF & 12 & 43 & 26 & $25 \%$ & 38 \\
Municipal & iMBR ADF & 8.4 & 25 & 18 & $24 \%$ & 38 \\
Municipal & AL-sMBR ADF & - & - & 50 & - & 1 \\
Food & iMBR, FS \& HF & 8.6 & 25 & 14 & $37 \%$ & 13 \\
Food & sMBR, pumped & 113 & 185 & 142 & $20 \%$ & 5 \\
Food & AL-sMBR & 31 & 44 & 39 & $18 \%$ & 3 \\
Other industrial & iMBR, FS \& HF & 8.5 & 28 & 14 & $34 \%$ & 23 \\
Leachate & iMBR, FS \& HF & 8.7 & 14 & 11 & - & 2 \\
Leachate & sMBR, pumped & 54 & 93 & 81 & $23 \%$ & 4 \\
\hline
\end{tabular}

The data also reflect the challenging nature of landfill leachate treatment. For the four examples of pumped sMBRs provided, the fluxes attained are considerably lower than those reported for food effluent treatment using the same MBR process configuration (81 vs. $142 \mathrm{LMH}$ on average, 
Table 1). Similarly, for the immersed configuration, the two flux data provided for iMBRs used for leachate treatment are both below $15 \mathrm{LMH}$ (Fig. 5b).

\subsection{Application of shear}

Evidence suggests that membrane air scour rates for industrial iMBRs do not differ from those employed for municipal wastewater treatment for the same commercial technology. Similarly, crossflows and pressures applied to AL sMBRs appear to be the same as those used for municipal wastewater treatment. Considering available data from municipal wastewater treatment, based on $14 \mathrm{iHF}$ and $14 \mathrm{iFS}$ installations, the $\mathrm{SAD}_{\mathrm{m}}$ values adopted for $\mathrm{iFS}$ technologies appear to be more scattered than those for iHF ones (Fig. 6), but this is primarily due to differences in the FS stacking. Single-deck FS systems demand more air per unit membrane area, with $\mathrm{SAD}_{\mathrm{m}}$ generally exceeding $0.7 \mathrm{Nm}^{3} \mathrm{~m}^{-2} \mathrm{hr}^{-1}$, than double-deck ones, where $\mathrm{SAD}_{\mathrm{m}}$ can be as low as 0.25 . For crossflow sMBRs the crossflow velocity employed depends on the process design and configuration, with conventional pumped systems operating at 3-4 m/s crossflow velocity compared with the more recent "low energy" pumped systems which operate at about half this CFV and a lower associated TMP, but also a reduced flux [22].

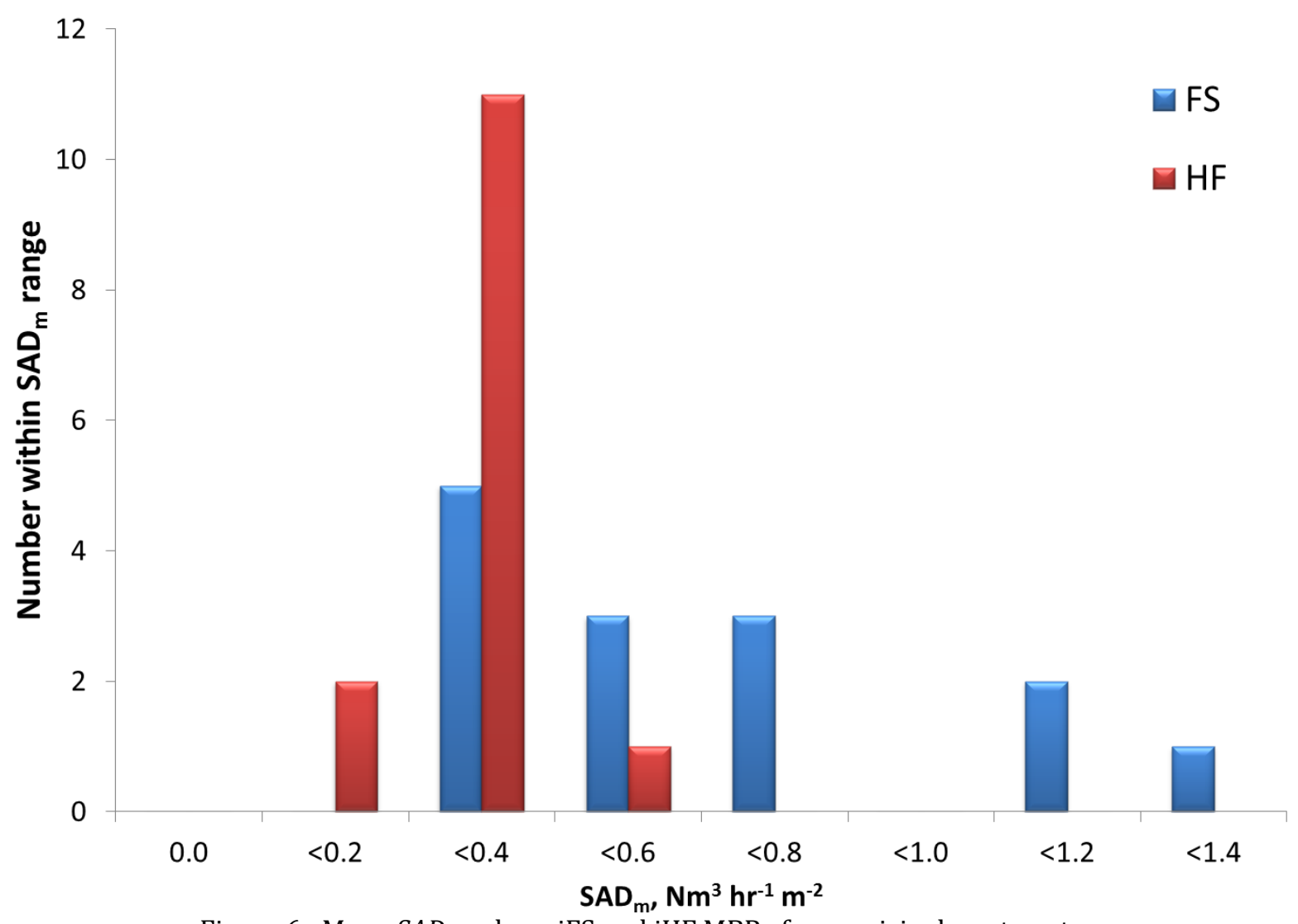

Figure 6. Mean $S A D_{m}$ values, iFS and iHF MBRs for municipal wastewaters

The physical and chemical cleaning parameters also do not generally change with application: relaxation and backflush cycles tend to be technology-specific, along with CIP (clean in place) protocols. However, the diversity in industrial effluent composition means that the risk of fouling by key inorganic foulant species, such as calcium carbonate scale, metal hydroxides and phosphates, may be higher for industrial applications and demand bespoke chemical cleaning measures. 


\subsection{Biotreatment}

Biological treatment is normally aerobic (Ae), though some anaerobic MBR installations exist. Biological nutrient removal (BNR) is normally achieved by a combination of these aerobic with anoxic (Ax) and anaerobic (An) conditions in the process tank conditions, recirculating the mixed liquor (or sludge) through the different tanks. Biological performance is considered for aerobic treatment.

The BOD/COD ratio is often assumed to provide an indication of treatability, and there are evidently some effluents which are significantly more biorefractory (i.e. resistant to biodegradation) than others such that carbonaceous removal is limited even at extended HRTs. Thus for municipal MBRs, which generally have a BOD/COD ratios between 0.4 and 0.6 [18], treated water BOD levels are generally below $2 \mathrm{mg} / \mathrm{L}$ for most installations operating under steady state conditions. For food and beverage effluents, for which the reported BOD/COD ratios are predominantly above 0.5 but have much higher feed COD concentration, MBR treatment achieves more than 90\% COD removal in all cases and at least 95\% on average for $75 \%$ of the installations reported (Fig. 7a). For landfill leachate, on the other hand, for which reported mean BOD/COD ratios are mainly below 0.3, only a third of the plants listed achieve $90 \%$ COD removal. The trend across the different wastewaters is similar for residual COD levels (Fig. 7b). Trends for all other industrial wastewater types appear to lie between these two extremes. Effective ammonia or TKN removal is almost always achieved, invariably down to below $20 \mathrm{mg} / \mathrm{L}$ regardless of application provided nitrification is not inhibited. In two thirds of the cases where ammonia and/or TKN levels were reported removal was down to $<5 \mathrm{mg} / \mathrm{L}$. This is perhaps unsurprising given the generally long SRTs afforded by MBR technology, which tends to encourage the development of the slow-growing nitrifiers.

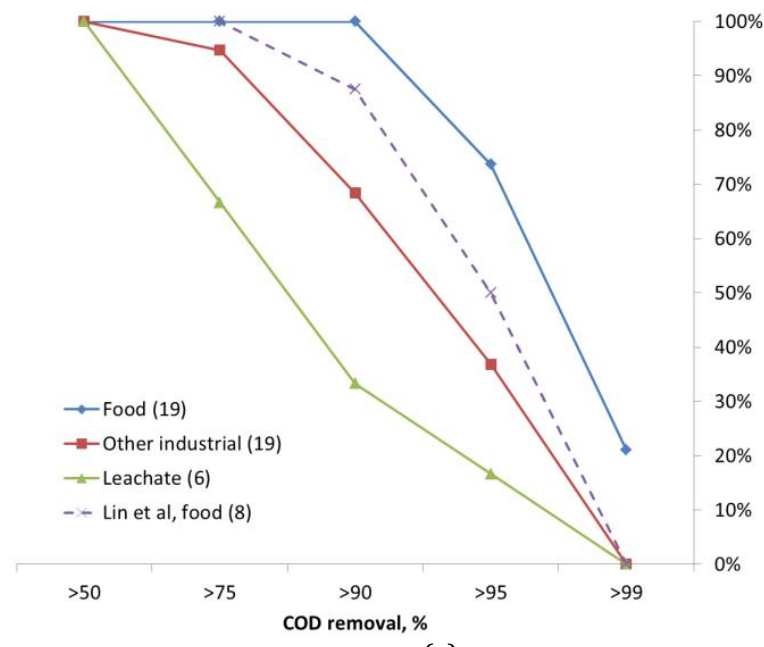

(a)

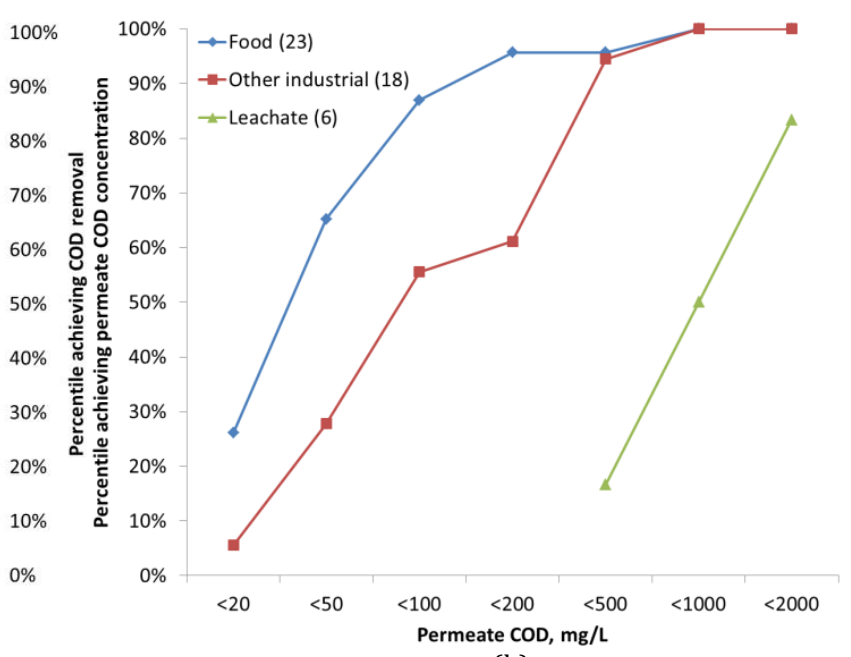

(b)

Figure 7. Overall trends in COD removal from industrial effluent (a) \% removed (dashed refers to data extracted from [8]), and (b) permeate COD concentration, for 52 and 47 reference sites respectively [4].

The reported performance in general, in terms of COD and N-NH 4 /TKN removal, appears to be somewhat better than that indicated by the predominantly bench-scale data reviewed by Lin et al. (2012) [8]. This is evident from a comparison of COD removal data for the most extensively reported application of food effluent treatment, for which eight sets of data are provided by Lin et al., compared with 19 industrial effluent treatment installations. Clearly, much larger data sets are needed for a more rigorous comparison but it is possible that this disparity reflects the acclimatisation period, since full-scale plants must necessarily achieve steady-state operation. 
MLSS concentrations employed appear to relate mainly to membrane or process configuration, with iFS membranes and sidestream configurations tending to operate at higher solids concentrations that iHF MBRs (Fig. 8). Whilst the data is highly scattered, it is consistent with the expected clogging propensity of the different configurations. HF membranes modules are more tightly packed than either FS or HF membranes [33] and are this more prone to clogging, demanding lower solids concentrations to ameliorate this issue. The higher loadings associated with the industrial effluents do not appear to correlate with a higher MLSS levels: the average levels are actually lower. This implies a higher F:M ratio for industrial effluents, which may then be associated with increased fouling [34].

Anaerobic MBRs have been applied at feed COD concentrations between 12,000 and 57,000 $\mathrm{mg} / \mathrm{L}$. Data revealed anaerobic MBR technologies to achieve removals of $>99 \%$ and residual COD levels of $<500 \mathrm{mg} / \mathrm{L}$ when challenged with high loads of readily biodegradable organic carbon (predominantly food and beverage industry effluents). As with any anaerobic treatment process, no nutrient removal is achieved and thus the viability of the process depends on the required treated water quality in this regard and/or downstream removal of the $\mathrm{N}$ and $\mathrm{P}$. Reported fluxes were generally in the range of 4-6 LMH for iFS systems and 15-25 LMH for sMT systems, reflecting the highly fouling nature of the anaerobic biomass. Some recent pilot studies [35] suggest that optimised operation combined with relatively low MLSS concentrations can allow fluxes as high as $20 \mathrm{LMH}$ to be sustained.

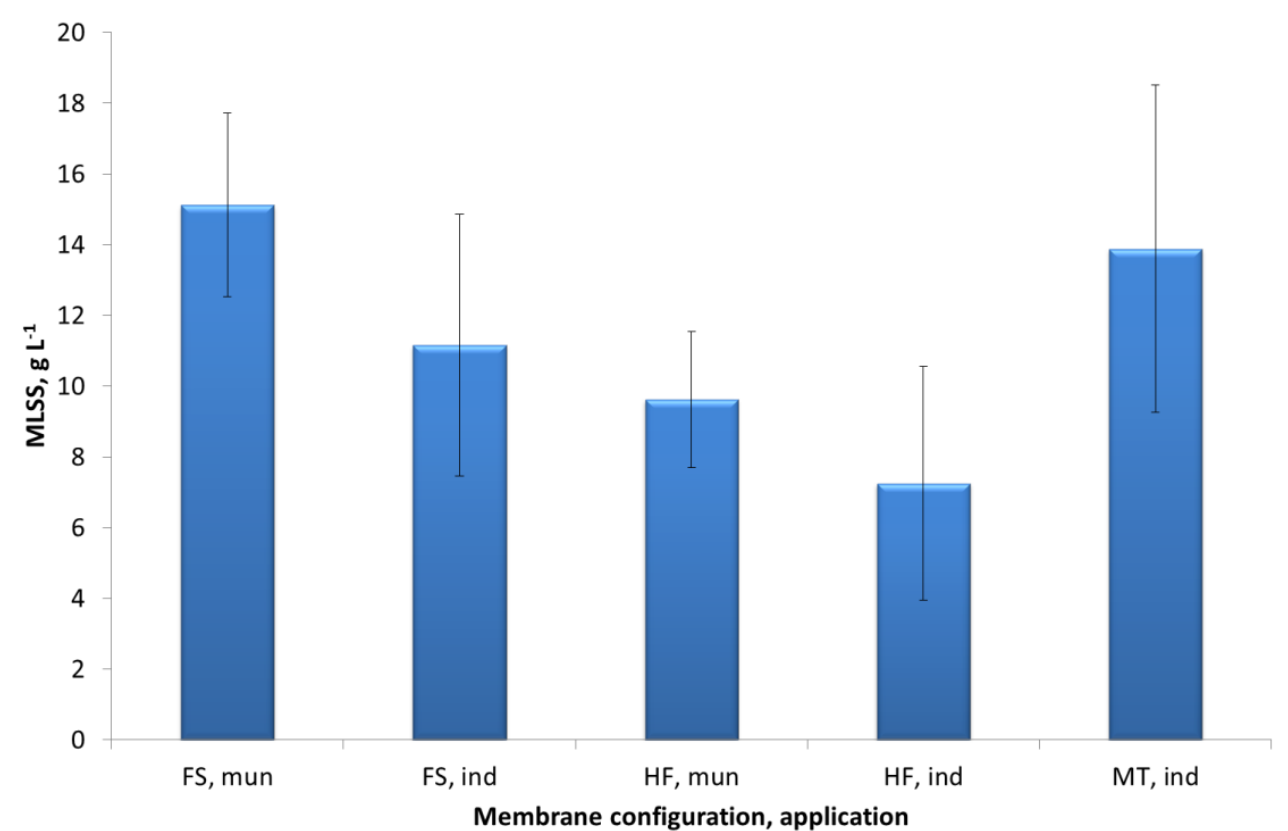

Figure 8. Mean MLSS concentrations according to membrane configuration and application

\section{Survey}

A survey of MBR stakeholders was conducted via The MBR Site (www.thembrsite.com) in February 2015. The survey was based on two questions. The first question was: In your experience, what are the main technical issues or limitations that prevent MBRs working as they should?, with ten elective answers plus a "comments" box. The second was an open question: In your opinion, how will MBR technology develop in the future? The survey received 186 responses, compared with 69 and 48 received for the same survey conducted in January 2012 and February 2010 respectively. Half of the respondents stated that their responses applied to both municipal and industrial wastewater treatment, whereas 29\% considered their answers to be more specific to municipal wastewaters and $17 \%$ to industrial effluents. Around a quarter of the 
respondents were membrane technology suppliers and at least $15 \%$ were academics, whereas only around 5\% were end users. Much of the remainder were contractors or consultants.

The 2015 survey was based on the same question and the same set of elective answers as the previous one from February 2012. The original 2010 survey [33] was an open question with a free response, and the responses provided were used formulate the answers to the subsequent surveys. The 2015 included an "other" option, which accounted for 5\% of the responses: the calculated percentages for the other 10 responses were normalised (i.e. divided by 0.95 ) to account for this.

Responses received were very similar to those from the February 2012 survey (Fig. 9a). All categories other overloading were within 2\% of 2012 survey responses. Also, as with the previous survey, the combined total for screening/pretreatment and clogging was comparable to that of overloading/under design and fouling. Clogging, and "ragging" in particular [36], is associated with insufficient pretreatment and both fouling and clogging with overloading. As with the previous two surveys, it appears that clogging of either the membrane channels or aerators remains as great a problem as membrane surface fouling. It is now recognised both from reported studies [36] and more widely from general observations by practitioners that suppression of clogging, and ragging in particular, demands tighter and well-maintained inlet screens, and possibly screening of the return activated sludge (RAS) stream. The only issues for which the absolute rating has increased by more than $2 \%$ were operator knowledge and energy demand. The focus on improved membrane air scour efficiency by some of the technology suppliers [37] is thus vindicated by this survey, since air scour presents the greatest contribution to energy demand by an operating MBR.

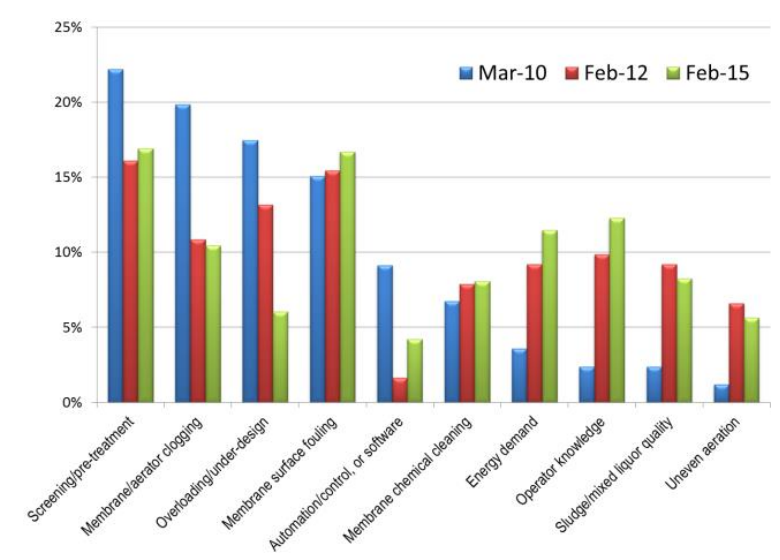

(a)

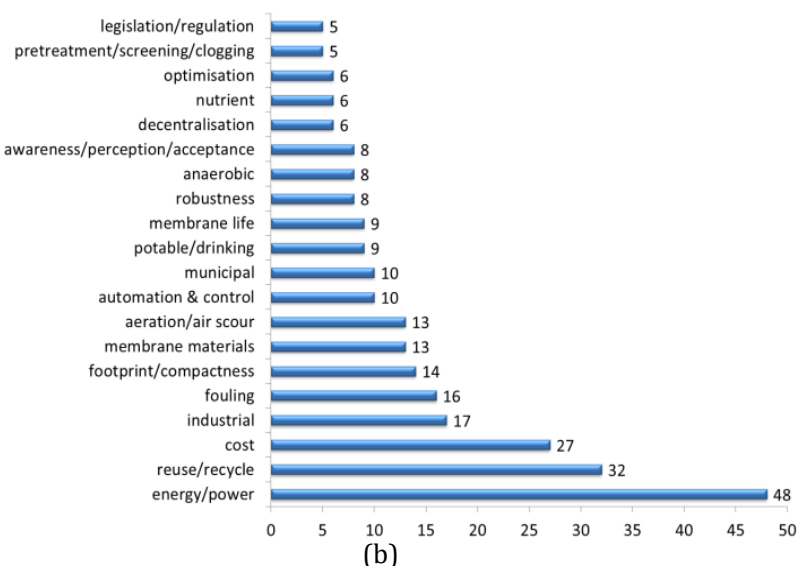

(b)

Figure 9. Responses to the survey (a) Q1: In your experience, what are the main technical issues or limitations that prevent MBRs working as they should? And (b) Keywords from the responses to the survey Q2: In your opinion, how will MBR technology develop in the future

The response to the open question on the future of MBRs generated 151 responses amounting to $\sim 4000$ words. All comments were collated in a single document, corrected for typographical errors, and analysed for the most frequent key terms. 20 keywords, along with their respective related terms (e.g. the terms "CAPEX", "OPEX", TOTEX and the root "expen" were all considered as one with the keywords "cost") were identified and summed across the whole document. In counting the terms a manual check was conducted to ensure that no rogue terms were inadvertently included.

Results of the analysis (Fig. 9b) indicated the related aspects of energy and cost to be two of the three most frequently mentioned. In terms of applications water reuse featured strongly, and 
industrial applications featured more prominently than municipal - perhaps reflecting the larger number of commercial opportunities. Key aspects such as nutrient removal and decentralisation also featured. Other key terms included legislation, optimisation and perception - encapsulating a key driver, challenge and barrier to the technology - along with process automation/control and, most prominently, footprint/compactness. Whilst the latter is a recognised driver for implementation, improved process automation and control is arguably one of the key aspirations for MBR technology [19] since sustaining the membrane flux at the lowest energy expenditure necessarily implies that applied shear (though membrane aeration or crossflow operation) must be adjusted accordingly. The identification of new membrane materials relates partly to the new ceramic technologies (Fig. 3), but also to the perceived requirement for more robust and antifouling materials. Reference to anaerobic technology again relates largely to minimising energy demand, as well as sludge production.

The reference made to cost by most respondents was predominantly negative, with both the membrane materials and the process operation perceived as being overly expensive. However, a number of analyses conducted within the past eight years [24, 38, 39] have concluded that the computed total cost can favour MBRs over classical technologies. Indeed, so long as significant nutrient removal is a requirement and/or the water is for reuse purposes (and in particular if it is to undergo reverse osmosis) an MBR is almost certainly likely to be lower in CAPEX than a classical activated sludge process for large-scale municipal wastewater treatment [39]. Such cost analyses are sensitive to the SED, which is in turn highly dependent on the extent to which the membrane air scour is matched to the feed flow. For a membrane component designed for peak hydraulic loads with no contingency for adjustment to slack flows, the SED increases inversely with the flow rate to values reportedly above $2 \mathrm{kWh} / \mathrm{m}^{3}$ at hydraulic loads of $20-25 \%$ of the peak flow [40]. For small flows, a far greater proportion of the specific cost (cost per unit treated water volume) is the labour cost [41]. In such cases it is generally more cost effective, over any reasonable amortisation period, to adopt a conservative approach to design and operation (and thus a comparatively high SED) so as to reduce manual intervention as far as possible.

This survey analysis did, however, reveal one or two contradictions. The importance of clogging as a technical limitation from Question 1 is not reflected in the responses to Question 2, with antifouling membranes considered to be a more important future development than clogging amelioration. Against this, aeration (including membrane air scour) featured as often as membrane materials in the responses.

\section{Conclusions}

A review of status of MBR technology with respect to the available commercial technologies, key design and performance parameters of existing installations, and stakeholder perception has revealed the following:

1. Of more than 55 commercial MBR membrane products considered almost $50 \%$ are based on polyvinylidene difluoride (PVDF), offered in all three membrane configurations (flat sheet, FS, hollow fibre, HF, and multitube, MT) and over a wide range of pore sizes. Polyethylsulphone (PES) is provided only as FS membranes at a single pore size of $0.03 \mu \mathrm{m}$, and polyolefinic membranes only in the HF configuration. Most products have a pore size between 0.03 and $0.4 \mu \mathrm{m}$.

2. Design fluxes in $\mathrm{L} \mathrm{m}^{-2} \mathrm{~h}^{-1}(\mathrm{LMH})$ for municipal wastewater treatment are predominantly in the 15-25 LMH range, 18.5 $\pm 4.8 \mathrm{LMH}$ on average, for average daily flow (ADF), and in the 20$30 \mathrm{LMH}, 26.0 \pm 6.6 \mathrm{LMH}$ on average, for peak daily flow (PDF). For industrial effluent treatment, for which flow generally undergoes equalisation of at least 8 hours to mitigate against the impact of significant changes in organic matter concentration, fluxes are lower 
and dependent on both process configuration and effluent quality. The most challenging effluents (landfill leachate) are associated with the lowest fluxes of around 9-14 LMH for an iMBRs and 54-93 LMH for a sidestream operation.

3. Treatment capability relates roughly to feedwater BOD/COD ratio, decreasing from municipal to food and beverage, textile/pulp and paper, and finally landfill leachate. For food and beverage effluents, for which BOD/COD ratios are mostly above 0.5 , more than $90 \%$ COD removal in all cases and at least $95 \%$ on average has been reported for $75 \%$ of the industrial effluent treatment installations - comparable with municipal wastewater treatment. Effluents with significantly more biorefractory content, the most challenging being landfill leachate for which mean BOD/COD ratios are mainly below 0.3 , only a third of the plants considered achieved 90\% COD removal. Effective ammonia or TKN removal is almost invariably achieved, down to below $20 \mathrm{mg} / \mathrm{L}$ regardless of application for industrial effluents and to below $2 \mathrm{mg} / \mathrm{L}$ for municipal wastewaters, provided no nitrification inhibition occurs.

4. Mixed liquor suspended solids (MLSS) concentrations relate primarily to MBR technology rather than application, with solids concentrations above $10 \mathrm{~g} / \mathrm{L}$ favoured for FS and MT membranes and below this threshold for HF membranes.

5. A survey of 186 stakeholders (around $85 \%$ of whom were practitioners, rather than academics) revealed membrane screening and membrane channel clogging to be viewed as being as onerous as membrane fouling and overloading, these pairs of phenomena both being inter-related. The similarity in the weighting of the responses across the various topics with a similar survey conducted three years ago suggest that there is little change in the perceived relative importance of the main challenges.

Whilst the challenges faced by MBR technologies are generic, as Figure 9 suggests, there are distinct differences in design approach when considering municipal and industrial applications. For small plants typical of industrial effluent treatment, where the cost of unscheduled intervention may be very onerous, a conservative design to minimise maintenance requirements is more critical than for the larger municipal plants, particularly when on site specialist knowledge is unavailable. This inevitably increases the operating cost, as reflected in the lower fluxes (Fig. 5) and generally higher air scour rates (Fig. 6). Notwithstanding this, the overriding impression from the survey, and the every-increasing MBR plant size (the largest prospective installation being the 864 MLD plant intended for Henriksdal near Stockholm), is one of increasing confidence in the technology. The challenges remain (Fig. 9), but appear not to be insurmountable.

\section{References}

[1] BCC, Membrane Bioreactors: Global Markets, BCC Report MST047B, June 2008.

[2] Frost and Sullivan, Global Membrane Bioreactor (MBR) Market, Report M7E2-01, January 2013.

[3] MarketsandMarkets, Membrane Bioreactor Systems Market by Application (Municipal Wastewater Treatment and Industrial Wastewater Treatment), by Type (Hollow Fiber, Flat Sheet, and Multi Tubular), by Configuration (Internal/Submerged and External/ Side stream), and by Region - Trends \& Forecasts to 2019, Report CH 2651, August 2014.

[4] L. Böhm, A. Drews, H. Prieske, P.R. Bérubé, M. Kraume, The importance of fluid dynamics for MBR fouling mitigation, Bioresource Technol. 122 (2012) 50-61.

[5] M.F.R. Zuthi, H.H. Ngo, W.S. Guo, Modelling bioprocesses and membrane fouling in membrane bioreactor (MBR): A review towards finding an integrated model framework. Bioresource Technol. 122 (2012) 119-129.

[6] M.F.R. Zuthi, H.H. Ngo, W.S. Guo, J. Zhang, S. Liang, A review towards finding a simplified approach for modelling the kinetics of the soluble microbial products (SMP) in an integrated mathematical model of membrane bioreactor (MBR). Internat. Biodeterioration Biodegrad. 85 (2013) 466-473.

[7] D.Q. Ran, L.G. Lu, W.D. Zhao, Y. Shang, A mini review of soluble microbial products in the membrane bioreactor systems, Appl Mechanics Mats. 641-642 (2014) 361-364. 
[8] H. Lin, W. Gao, F. Meng, B.Q. Liao, K.T. Leung, L. Zhao, J. Chen, H. Hong, Membrane Bioreactors for Industrial Wastewater Treatment: A Critical Review. Crit. Revs. Environ. Sci. Technol. 42 (2012) 677-740.

[9] Mutamim, N. S. A., Noor, Z. Z., Hassan, M. A. A., \& Olsson, G. (2012). Application of membrane bioreactor technology in treating high strength industrial wastewater: A performance review. Desalination, 305, 1-11.

[10] M.F.R. Zuthi, W.S. Guo, H.H. Ngo, L.D. Nghiem, F.I. Hai (2013). Enhanced biological phosphorus removal and its modeling for the activated sludge and membrane bioreactor processes. Bioresource Technology, 139, 363-374.

[11] X. Zheng, P. Sun, J. Han, Y. Song, Z. Hu, H. Fan, S. Lv, Inhibitory factors affecting the process of enhanced biological phosphorus removal (EBPR) - A mini-review. Proc. Biochem. 49:12 (2014) 2207-2213

[12] C. Li, C. Cabassud, C. Guigui,Evaluation of membrane bioreactor on removal of pharmaceutical micropollutants: A review. Desal. Water Treat. 55:4 (2015) 845-858

[13] R. Reif, F. Omil, J.M. Lema, Removal of pharmaceuticals by membrane bioreactor (MBR) technology. Comprehensive Analytical Chemistry 62 (2013) 287-317.

[14] Fenu, G. Guglielmi, J. Jimenez, M. Spèrandio, D. Saroj, B. Lesjean, C. Brepols, I. Nopens, Activated sludge model (ASM) based modelling of membrane bioreactor (MBR) processes: A critical review with special regard to MBR specificities. Water Res. 44:15 (2010) 4272-4294.

[15] S.I. Patsios, A.J. Karabelas, A review of modeling bioprocesses in membrane bioreactors (MBR) with emphasis on membrane fouling predictions. Desal. Water Treat. 21:1-3 (2010) 189-201.

[16] W. Naessens, T. Maere, I. Nopens, Critical review of membrane bioreactor models - part 1: Biokinetic and filtration models. Bioresource Technology 122 (2012) 95-106.

[17] W. Naessens, T. Maere, N. Ratkovich, S. Vedantam, S., I. Nopens. Critical review of membrane bioreactor models - part 2: Hydrodynamic and integrated models. Bioresource Technol. 122 (2012) 107-118.

[18] P. Wei, K. Zhang, W. Gao, L. Kong, R. Field, CFD modeling of hydrodynamic characteristics of slug bubble flow in a flat sheet membrane bioreactor. J. Membrane Sci. 445 (2013) 15-24.

[19] G. Ferrero, I. Rodríguez-Roda, J. Comas. Automatic control systems for submerged membrane bioreactors: A state-of-the-art review. Water Research 46:11 (2012) 3421-3433.

[20] S. Judd. Industrial MBRs, Judd and Judd, Cranfield, 2014.

[21] Frost \& Sullivan (2011b): China Membrane Bioreactor (MBR) Market Outlook - Ambitious Water Reuse Targets to Boost Local Membrane Industry and Fuel Exponential Growth.

[22] S. Judd. The MBR Book, 2nd Edition, Butterworth-Heinemann, Oxford, 2011.

[23] C. Brepols. Operating large-scale membrane bioreactors for municipal wastewater treatment, IWA Publishing, London, 2011.

[24] C. Brepols, H. Schäfer, N. Engelhardt, Considerations on the design and financial feasibility of fullscale membrane bioreactors for municipal applications. Water Sci. Technol 61:10 (2010) 2461-2468.

[25] G.T. Daigger, A. Hodgkinson, S. Aquilina, P. Burrowes, Creation of a sustainable water resource through reclamation of municipal and industrial wastewater in the Gippsland Water Factory. J. Water Reuse Desalination 03.1 (2013) 1-15.

[26] H. Itokawa, K. Tsuji, K. Yamashita, T. Hashimoto, Design and operating experiences of full-scale municipal membrane bioreactors in Japan. Water Sci. Technol. 69:5 (2014) 1088-1093.

[27] M. Stone, D. Livingston, Flat plate MBR energy consumption, village of Dundee, MI., WEF Membrane Technology Conference, Alexandria, VA., 8-10 Jan 2008.

[28] G. Tao, K. Kekre, M.-H. Oo, B. Viswanath, C.-H. Lew, L.-M. Kan, H. Seah, Large scale membrane bioreactor plant design (retrofit) and optimisation. 5th IWA Specialised Membrane Technology Conference for Water \& Wastewater Treatment, Beijing, 1-3 Sep 2009.

[29] T. van Loggenburg, D. Herold, C. Kullmann (2010). Membrane bioreactors (MBR) for landfill leachate treatment, International Biennial Conference \& Exhibition, Durban, 18-22 April 2010.

[30] LIWATEC Laymen Report, Textil-Service Klingelmeyer GmbH \& Co. KG, 2005.

[31] Huber Technology, waste water solutions. Membrane technology for wastewater recycling in textile industry. http://www.huber.de/huber-report/ablage-berichte/industry/membrane-technology-forwastewater-recycling-in-textile-industry.html (accessed July 2014).

[32] M. Henze, P. Harremoës, J. la Cour Jansen, E. Arvin, Wastewater Treatment: Biological and Chemical Processes, 3rd ed, Springer-Verlag, Berlin, 2002.

[33] A. Santos, W.-J. Ma, S. Judd, Membrane bioreactor technology: two decades of research and implementation, Desalination, 273 (2011) 148-154 
[34] B. Wu, T. Kitade, T.H. Chong, J.Y. Lee, T. Uemura, A.G. Fane, Flux-dependent fouling phenomena in membrane bioreactors under different food to microorganisms (F/M) ratios, Sep. Sci. Technol. (2013) 48:6 840-848

[35] R. Pretel, A. Robles, M. V. Ruano, A. Seco, J. Ferrer, The operating cost of an anaerobic membrane bioreactor (AnMBR) treating sulphate-rich urban wastewater. Separation and Purification Technology, 126 (2014) 30-38.

[36] S. Gabarrón, M. Gómez, H. Monclús, I. Rodríguez-Roda, J. Comas, Ragging phenomenon characterisation and impact in a full-scale MBR. Water Sci. Technol. 67:4 (2013) 810-816.

[37] Ginzburg, B. (2013). LEAPmbr Process Design. MEA UFMBR Workshop for ITPs, 4-7 November, Abu Dhabi.

[38] J. DeCarolis, S. Adham, W.R. Pearce, Z. Hirani, S. Lacy, R. Stephenson, Cost trends of MBR systems for municipal wastewater treatment, Proceedings of the Water Environment Federation, 13-17 October 2007, San Diego, 3407-3418.

[39] T. Young, M. Muftugil, S. Smoot, J. Peeters, MBR vs. CAS: Capital and operating cost evaluation, Water Practice Technol. 7:4 (2012).

[40] S. Gabarrón, G. Ferrero, M. Dalmau, J. Comas, I. Rodríguez-Roda, Assessment of energy-saving strategies and operational costs in full-scale membrane bioreactors. J. Environ. Manag. 134 (2014) 814.

[41] B. Verrecht, C. James, E. Germain, R. Birks, A. Barugh, P. Pearce, S. Judd, Economical evaluation and operating experiences of a small scale MBR for non-potable reuse, J. Environ. Eng. 138 (2012) 594. 